\title{
BRUNS, Claudia, Politik des Eros, Der Männerbund in Wissenschaft, Politik und Jugendkultur (1880-1934)
}

\section{Paul Pasteur}

\section{OpenEdition}

\section{Journals}

Édition électronique

URL : http://journals.openedition.org/ifha/1855

DOI : 10.4000/ifha.1855

ISSN : 2198-8943

\section{Éditeur}

IFRA - Institut franco-allemand (sciences historiques et sociales)

\section{Référence électronique}

Paul Pasteur, «BRUNS, Claudia, Politik des Eros, Der Männerbund in Wissenschaft, Politik und Jugendkultur (1880-1934) », Revue de l'IFHA [En ligne], Date de recension, mis en ligne le 01 janvier 2009, consulté le 22 septembre 2020. URL : http://journals.openedition.org/ifha/1855 ; DOI : https:// doi.org/10.4000/ifha. 1855

Ce document a été généré automatiquement le 22 septembre 2020.

(C)IFHA 


\title{
BRUNS, Claudia, Politik des Eros, Der Männerbund in Wissenschaft, Politik und Jugendkultur (1880-1934)
}

\author{
Paul Pasteur
}

1 Derrière ce titre séduisant se cache en fait une étude ayant pour thème principal la théorie du Männerbund chez Hans Blüher (1888-1955), écrivain, philosophe et militant des Wandervögel. Dans une introduction d'une quarantaine de pages, l'auteure présente son sujet et entend faire le point sur les études concernant la masculinité, bilan qui se limite en général aux productions allemandes ou aux traductions en allemand ; on s'étonnera par exemple de ne pas voir citer les travaux publiés dans la revue féministe L'Homme. À la page 14, C.B. présente sa «thèse » selon laquelle la « formation du sujet masculin aussi bien individuel que collectif (Männerbund, État) » est le résultat de " rationalités discursives semblables, par des inclusions et exclusions semblables ». Pour elle, la théorie du Männerbund peut être déterminante aussi bien pour le sujet que pour le rapport entre le sujet au collectif, les deux niveaux se renforçant l'un l'autre, agissant l'un sur l'autre.

Elle entend démontrer cela en huit chapitres. Elle revient tout d'abord très rapidement sur les mouvements féministes et sur l'antiféminisme au tournant du siècle, puis sur la notion de Männerbund telle qu'elle a pu être mise en avant par le Suisse Johann Jakob Bachhofen dans un texte datant de 1861 « Mutterrecht » ainsi que dans les travaux de Schurtz de 1902. Dans un troisième chapitre, elle revient sur la «(homo)-sexualité » en tant que sociabilité virile, mais ce qui l'intéresse fondamentalement, ce sont les courants dits " masculinistes " des mouvements homosexuels. Dans un quatrième chapitre, elle interroge l'association entre homosexualité et politique à travers la presse à sensation, les scandales dans l'entourage de Guillaume II. Le chapitre V revient sur le personnage central pour elle dans la construction du concept de Männerbund : Hans Blüher. Les trois chapitres suivants sont consacrés aux conceptions et écrits de Hans Blüher, tout d'abord à sa perception du mouvement des Wandervögel en tant que «Männerbund homoérotique » puis aux réactions aux écrits de Hans Blüher au sein des 
Wandervögel, mais aussi dans les milieux völkisch ; enfin, C.B. aborde son antisémitisme et son antiféminisme. Dans sa conclusion, elle tient à démontrer la permanence d'une variante libérale du Männerbund de Bachofen à Baeumler en passant par Hans Blüher.

3 L'ouvrage est complété par la liste des sources, des périodiques consultés et la bibliographie - rappelons néanmoins qu'il existe une bibliographie annotée et commentée par Bernd-Ulrich Hergemöller qui a paru en 2004. On regrettera pour un tel ouvrage qu'aucun index n'ait été intégré.

4 Chez les historiens, la démarche de C.B. n'emportera certainement pas l'adhésion immédiate. Les historiens des idées seront peut-être plus réceptifs, bien que l'on puisse regretter que Hans Blüher soit surévalué au détriment d'autres contemporains comme Otto Weiniger, et que même dans l'optique d'une lecture genrée qui s'intéresserait prioritairement à la construction de la masculinité, le mouvement des Wandervögel ne soit perçu que sous le seul angle des écrits et théories de Hans Blüher. Quant à l'influence de Hans Blüher, on aimerait mieux la cerner : certes, son ouvrage Die Rolle der Erotik in der männlichen Gesellschaft en était en 1924 à un tirage de 15000 exemplaires, mais qu'en était-il de ses lecteurs et lectrices?

Paul PASTEUR (Université de Rouen) 